\title{
Solubility and pH of bioceramic root canal sealers: A comparative study
}

\author{
Claudio Poggio ${ }^{1}$, Alberto Dagna ${ }^{1}$, Matteo Ceci ${ }^{1}$, Maria-Vittoria Meravini ${ }^{1}$, Marco Colombo ${ }^{1}$, Giampiero \\ Pietrocola $^{2}$
}

${ }^{1}$ Department of Clinical-Surgical, Diagnostic and Pediatric Sciences, Section of Dentistry, University of Pavia, Italy

${ }^{2}$ Department of Molecular Medicine, Unit of Biochemistry, University of Pavia, Italy

Correspondence:

Department of Clinical-Surgical

Diagnostic and Pediatric Sciencees

Section of Dentistry, Policlinic "San Matteo"

Piazzale Golgi 3, 27100 Pavia, Italy

claudio.poggio@unipv.it

Poggio C, Dagna A, Ceci M, Meravini MV, Colombo M, Pietrocola G. Solubility and $\mathrm{pH}$ of bioceramic root canal sealers: A comparative study. J Clin Exp Dent. 2017;9(10):e1189-94.

http://www.medicinaoral.com/odo/volumenes/v9i10/jcedv9i10p1189.pdf

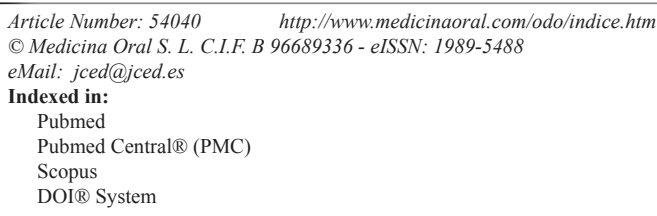

\begin{abstract}
Background: This study compared the solubility and the $\mathrm{pH}$ of different root canal sealers in vitro.

Material and Methods: BioRoot ${ }^{\mathrm{TM}} \mathrm{RCS}$, TotalFill BC Sealer, MTA Fillapex, SealapexTM, AH Plus, EasySeal, Pulp Canal Sealer ${ }^{\mathrm{TM}}$ and $\mathrm{N} 2$ were tested. Similar specimens were prepared using ring molds with an internal diameter of $20 \pm 0,1 \mathrm{~mm}$ and a height of 1,5 $\pm 0,1 \mathrm{~mm}$ and digitally weighted to register the mass of each specimen before and after immersion in distilled water. Solubility was determined after 24 hours and statistically analysed using a one-way ANOVA test and post-hoc Tukey test. The $\mathrm{pH}$ value was measured by a digital $\mathrm{pH}$ meter after 3 and 24 hours from manipulation.

Results: BioRoot ${ }^{\mathrm{TM}} \mathrm{RCS}$ and TotalFill BC Sealer showed significantly higher solubility $(P<0.05)$. All the remnant root canal sealers fulfilled the requirements of solubility of the International Standard Organization 6876 demonstrating a weight loss of less than $3 \%$. BioRoot ${ }^{\mathrm{TM}} \mathrm{RCS}$ and Totalfill $\mathrm{BC}$ Sealer exhibited high alkaline $\mathrm{pH}$ over time $(P<0.05)$; the alkalinity of the other tested cements was significantly lower.

Conclusions: The prolonged alkalinity of bioceramic sealer matched the increase in solubility. This may encourage their biological and antimicrobial effects, but the ongoing solubility may impact their ability to prevent apical leakage.
\end{abstract}

Key words: $p H$, root canal sealers, solubility.

\section{Introduction}

Endodontic sealers are used to obtain a stable seal of the root canal systems by the filling of discrepancies between the dentinal wall and gutta-percha (1). Root canal sealers and gutta-percha entomb residual micro- organisms, prevent the access of any bacteria from the oral environment and avoid their passage to the periapical tissues, thus aiding the healing of periapical lesions (2). An ideal sealer should offer specific properties $(3,4)$ and insolubility is one of the most desiderable physical 
property for root canal sealers (5) because it may have a great impact on the success rate of root canal treatment (2). In fact, degradation of the sealer may cause gaps along the sealer/dentin or the sealer/gutta-percha interface which might provide a pathway for microorganisms and their toxic products into periapical tissues $(5,6)$. Low solubility of a root canal sealer has been introduced in 2000 as a requirement in the ANSI/ADA specification No. 57 and in 2001 as a requirement in the International Standards Organization 6876 standard for root canal sealing materials. According to those standards the solubility of a sealer shall not exceed 3\% mass fraction after immersion in water for 24 hours (7).

In addition, the $\mathrm{pH}$ change of sealers may be related with antimicrobial effects and deposition of mineralized tissue, thus playing a role in the healing process (8). Alkaline $\mathrm{pH}$ of root canal sealers could neutralize the lactic acid from osteoclasts and prevent dissolution of mineralized components of teeth (9).

Today different types of endodontic sealers are available: zinc-oxide eugenol ( $\mathrm{ZnOE})$, resin-based, calcium hydroxide containing, MTA and bioceramic-based root canal sealers (10). The $\mathrm{ZnOE}$ sealers have a long history of successful usage, because of their widely demonstrated positive qualities (4). Calcium hydroxide containing sealers supposedly have antimicrobical effects and biologic properties that stimulate a calcific barrier at the apex (4). Epoxy-based cements are the primarily ones amongst resin-based sealers, with many tested properties like antimicrobial action, adhesion to dentin walls, good sealing ability and relative insolubility (4). Because of its favorable biological characteristics, root canal sealers based on mineral trioxide aggregate (MTA) have been introduced $(11$,$) . However, the handling characte-$ ristics of MTA preclude the use as a sealer without the addition of chemicals that provide sufficient flow (12). Components such as gels or water-soluble polymers have been added to enhance the cement manipulation $(12,13)$. Various studies reported the biocompatibility of MTA endodontic sealers, which may stimulate mineralization and exhibit bioactivity by stimulating hydroxyapatite nucleation (14).

Recently, bioceramic-based sealers containing calcium silicate and/or calcium phosphate attracted considerable attention because of their physical and biological properties such as their alkaline $\mathrm{pH}$, chemical stability within the biological environment, and lack of shrinkage (15) Bioceramic materials contain calcium phosphate which enhances the setting properties of bioceramics and results in a chemical composition and crystalline structure similar to tooth and bone apatite materials, thereby improving sealer-to-root dentin bonding (16).

The purpose of this in vitro study was to evaluate solubility at 24 hours and $\mathrm{pH}$ at 3 and 24 hours of new bioceramic-based sealers root canal sealers comparing them to conventional sealers. The null hypothesis tested was that there is no significant difference among root canal sealers tested.

\section{Material and Methods}

Eight different root canal sealers were tested: BioRoot ${ }^{\mathrm{TM}}$ RCS, TotalFill BC Sealer, MTA Fillapex, Sealapex ${ }^{\mathrm{TM}}$, AH Plus, EasySeal, Pulp Canal Sealer ${ }^{\mathrm{TM}}$, N2 (Table 1). -Solubility test

Solubility was determined in accordance with the International Standards Organization (ISO) 6876 method and with the American Dental Association (ADA) specification No. 57. The ISO 6876 standard specifies requirements for "materials used for permanent obturation of the root canal with or without the aid of obturating points". Stainless steel ring molds with an internal diameter of $20 \pm 0,1 \mathrm{~mm}$ and a height of 1,5 $\pm 0,1 \mathrm{~mm}$ were used for samples preparation. All moulds were cleaned with acetone in an ultrasound bath for 15 minutes and weighted 3 times before use (accuracy $\pm 0,0001 \mathrm{~g}$ ) using a precision balance (Mettler-Toledo, model AE1633, Novate Milanese, Italy). They were then placed on a glass plate, filled to slight excess with the mixed materials and covered with another glass plate under a light pressure in order to remove any exceeding material. All root-canal sealers were mixed and prepared by the same operator in accordance with manufacturer's instructions. Ten sets of specimens for each material were prepared. All samples set into an incubator at $37^{\circ} \mathrm{C}$ and $>95 \%$ relative humidity (Thermo Fisher Scientific, Waltham, MA, USA) for a period corresponding to three times the setting time. The excess of water was removed with absorbent paper and the samples were weighed 3 times. The average reading was recorded to 3 decimal places. The samples were placed two by two into a Petri dish containing $50 \mathrm{~mL}$ of distilled water and transferred into the same incubator at $37^{\circ} \mathrm{C}$ and $>95 \%$ relative humidity for 24 hours. After incubation time, the samples were rinsed with $3 \mathrm{~mL}$ of distilled water and the washings were allowed to drain back into the Petri dish. The samples were then discarded, and the Petri dishes were dried in an oven at $105{ }^{\circ} \mathrm{C}$ for 48 hours (Thermo Fisher Scientific, Waltham, MA, USA), cooled down in the same desiccator and reweighted. The difference between the final mass and the initial mass of the Petri dish divided by the initial dry weight of the sample $\mathrm{x} 100$ correspond to the loss of mass of each specimen express as percentage of solubility $(7,16)$. The solubility test was repeated 2 months after by using the same method (7). Analysis of variance (ANOVA) was applied to determine whether significant differences existed among the groups. For the post-hoc test, the Tukey's test was used. Significance for all statistical tests was predetermined at $P<0.05$.

- $\mathrm{pH}$ measurements

Root canal sealers were mixed and placed onto cylindri- 
Table 1: Root canal sealers tested.

\begin{tabular}{|c|c|c|c|c|}
\hline Group & Materials & Type & Manufacturer & Lot. No \\
\hline 1 & BioRoot $^{\mathrm{TM}}$ RCS & Bioceramic-based sealer & $\begin{array}{l}\text { Septodont, Saint-Maur-des- } \\
\text { Fosses, France }\end{array}$ & B15847 \\
\hline 2 & TotalFill BC Sealer & Bioceramic-based sealer & $\begin{array}{c}\text { FKG Dentaire SA La } \\
\text { Chaux-de-Fonds, } \\
\text { Switzerland }\end{array}$ & K21RA \\
\hline 3 & MTA Fillapex & Bioceramic-based sealer & $\begin{array}{l}\text { Angelus Dental Solutions, } \\
\text { Londrina, PR, Brazil }\end{array}$ & 37723 \\
\hline 4 & Sealapex ${ }^{\mathrm{TM}}$ & $\begin{array}{l}\text { Calcium hydroxide-based } \\
\text { sealer }\end{array}$ & Kerr, Orange, CA, U.S.A & 5779407 \\
\hline 5 & AH Plus & Epoxy resin-based sealer & $\begin{array}{c}\text { Dentsply-DeTrey Konstanz, } \\
\text { Germany }\end{array}$ & 1511000326 \\
\hline 6 & EasySeal & Epoxy resin-based sealer & $\begin{array}{c}\text { Komet, Brasseler GmbH \& } \\
\text { Co., Lemgo, Germany }\end{array}$ & BK01051015 \\
\hline 7 & Pulp Canal Sealer ${ }^{\mathrm{TM}}$ & $\begin{array}{l}\text { Zinc-oxide and eugenol } \\
\text { sealer }\end{array}$ & Kerr, Orange, CA, U.S.A & 5312732 \\
\hline 8 & $\mathrm{~N} 2$ & $\begin{array}{l}\text { Zinc-oxide and eugenol } \\
\text { sealer }\end{array}$ & $\begin{array}{c}\text { Ghimas S.p.A } \\
\text { Casalecchio di Reno, BO, Italy }\end{array}$ & $04-13$ \\
\hline
\end{tabular}

cal Teflon moulds 2-mm-height and 10-mm-diameter and set into an incubator at $37^{\circ} \mathrm{C}$ and $>95 \%$ relative humidity (Thermo Fisher Scientific, Waltham, MA, USA). Six samples were prepared for each group and were placed into separate vials containing $10 \mathrm{~mL}$ of distilled water. The samples were stored at $37^{\circ} \mathrm{C}$ and $\mathrm{pH}$ measurement was performed 3 and 24 hours after incubation. The $\mathrm{pH}$ values were measured by a digital $\mathrm{pH}$ meter (OrionTM pH Meter 420A, Orion Research Inc., Boston, MA, USA) calibrated with buffer solutions (Orion buffer solution, Perfect buffer 10, Orion Research Inc. [pH=4,01; $\mathrm{pH}=7,00 ; \mathrm{pH}=10,00])$ before each experiment. After removal of the specimens, the container was placed in an orbital shaker (R\&D Labs srl, Saronno, Italy) for $5 \mathrm{sec}$ before measuring. The temperature of the room during the test was $25^{\circ} \mathrm{C}$. Tukey's test was applied to determine whether significant differences existed in $\mathrm{pH}$ values after 3 hours of incubation. To determine whether time influenced the $\mathrm{pH}$ values of the root canal sealers, an analysis of longitudinal data was performed using t-test for paired data $(P<0.05)$ between times of incubation ( 3 and 24 hours).

\section{Results}

-Solubility (\%)

The results of solubility test are listed in Table 2. BioRoot ${ }^{\mathrm{TM}} \mathrm{RCS}$ and TotalFill BC Sealer showed significantly higher $(P<0.05)$ solubility among the tested

Table 2: Mean percentage values of solubility and standard deviation (SD) for each material.

\begin{tabular}{|c|c|}
\hline Material & $\begin{array}{c}\text { Solubility (\%) } \\
\text { Mean (SD) }\end{array}$ \\
\hline Bioroot $^{\mathrm{TM}} \mathrm{RCS}$ & $11.05 \%(1.25)$ \\
\hline TotalFill BC Sealer & $13.12 \%(1.43)$ \\
\hline EasySeal & $0.69 \%(0.07)$ \\
\hline MTA Fillapex & $1.76 \%(0.28)$ \\
\hline Pulp Canal Sealer ${ }^{\mathrm{TM}}$ & $0.10 \%(0.05)$ \\
\hline Sealapex $^{\mathrm{TM}}$ & $0.94 \%(0.13)^{\mathrm{A}}$ \\
\hline AH Plus & $0.045 \%(0.01)$ \\
\hline $\mathrm{N} 2$ & $0.93 \%(0.18)^{\mathrm{A}}$ \\
\hline
\end{tabular}

The same capital letter indicates no significant differences $(P>0.05)$ among groups. 
materials, although the highest solubility percentage was recorded for Totalfill BC Sealer. All remnant root canal sealers (EasySeal; MTA Fillapex; Pulp Canal Sealer' ${ }^{\text {TM}}$; Sealapex ${ }^{\mathrm{TM}}$; AH Plus and N2) fulfilled the requirements of the International Standard Organization 6876 and the ANSI/ADA specification No. 57 for endodontic sealing materials (Chicago, USA, 2000), demonstrating a weight loss of less than 3\%. AH Plus provided the lowest solubility, significantly lower $(P<0.05)$ than all the tested sealers. Pulp Canal Sealer ${ }^{\mathrm{TM}}$, N2, Sealapex ${ }^{\mathrm{TM}}$, EasySeal and MTA Fillapex showed solubility values significantly lower $(P<0.05)$ than BioRoot ${ }^{\mathrm{TM}} \mathrm{RCS}$ and TotalFill BC Sealer but significantly higher $(P<0.05)$ than AH Plus. No significant differences were found between Pulp Canal SealerTM, Sealapex ${ }^{\mathrm{TM}}$ and N2. Solubility values in increasing order were: AH Plus $<$ Pulp Canal Sealer $^{\mathrm{TM}}<\mathrm{N} 2<$ Sealapex ${ }^{\mathrm{TM}}<$ EasySeal $<$ MTA Fillapex $<$ BioRoot ${ }^{\mathrm{TM}} \mathrm{RCS}<$ TotalFill BC Sealer.

-pH changes

The $\mathrm{pH}$ mean values of all tested materials at different immersion times ( 3 and $24 \mathrm{~h}$ ) are described in Table 3.

\section{Discussion}

Root canal sealers have to provide an apical seal avoiding the leakage of irritants and pathogens from the root canal system into the periradicular tissues (4). Solubility is an important factor in assessing the suitability of dental materials in dentistry: it's defined as the ability of a substance to dissolve in another and it's expressed as the concentration of the saturated solution of the former in the latter (17). The solubility of the root canal sealers shall not exceed 3\% mass fraction after immersion in water for 24 hours, when determined in accordance to the International Standards Organization 6876 standard or ANSI/ ADA Specification No. 57. The solubility test performed in the present study fulfilled these standards. This kind of test is significant because root canal sealers can get direct contact with periapical tissues fluids in apical region (18). MTA-based and bioceramic sealers have been introduced in endodontics for advantages like their biocompatibility that prevents rejection by the surrounding tissues and improved sealer-to-root dentin bonding, due to the deposition of bone apatite materials (19).

Table 3: Mean $\mathrm{pH}$ values and standard deviation (SD) for each the tested materials at 3 and 24 after incubation.

\begin{tabular}{|c|c|c|}
\hline \multirow[t]{2}{*}{ Material } & \multicolumn{2}{|c|}{ pH } \\
\hline & $3 \mathrm{~h}$ & $24 h$ \\
\hline Bioroot $^{\mathrm{TM}}$ RCS & $11.25(1.12)$ & $11.43(0.07)$ \\
\hline TotalFill BC Sealer & $10.06(1.24)$ & $10.67(1.25)$ \\
\hline EasySeal & $8.40(0.14)^{\mathrm{A}}$ & $8.39(0.28)^{\mathrm{A}}$ \\
\hline MTA Fillapex & $7.68(0.51)$ & $8.02(0.31)$ \\
\hline Pulp Canal Sealer ${ }^{\mathrm{TM}}$ & $8.07(0.32)^{\mathrm{a}}$ & $7.55(0.60)^{\mathrm{a}}$ \\
\hline Sealapex ${ }^{\mathrm{TM}}$ & $9.72(0.84)^{\mathrm{B}}$ & $9.63(1.07)^{\mathrm{B}}$ \\
\hline AH Plus & $8.08(0.92)^{\mathrm{a}}$ & $7.78(0.91)^{\mathrm{a}}$ \\
\hline N2 & $7.13(0.56)^{\mathrm{C}}$ & $6.98(0.16)^{\mathrm{C}}$ \\
\hline
\end{tabular}

The same superscript letter indicates no significant differences $(P>0.05)$ among groups in vertical row. Capital letters refer to t-test for paired data. The same capital letters indicate no significant differences in time (horizontal row) $(P>0.05)$.

BioRoot ${ }^{\mathrm{TM}} \mathrm{RCS}$, Totalfill BC Sealer and Sealapex ${ }^{\mathrm{TM}}$ exhibited high alkaline $\mathrm{pH}$ values over time, although the significantly highest alkaline $\mathrm{pH}$ score was recorded for TotalFill BC Sealer $(P<0.05)$. No significant variation in $\mathrm{pH}$ was observed for Sealapex Root Canal Sealer over time, whereas it was significant for both BioRoot ${ }^{\mathrm{TM}} \mathrm{RCS}$ and TotalFill BC Sealer $(P<0.05)$. Significantly lower $(P<0.05)$ was the alkalinity of EasySeal, MTA Fillapex, Pulp Canal Sealer ${ }^{\mathrm{TM}}$ and AH Plus than that observed for BioRoot ${ }^{\mathrm{TM}} \mathrm{RCS}$, TotalFill BC Sealer and Sealapex ${ }^{\mathrm{TM}}$. MTA Fillapex exhibited initial neutral $\mathrm{pH}$ (7.68) followed by a weak alkaline pH (8.02). Pulp Canal Sealer ${ }^{\mathrm{TM}}$ and AH Plus had initial weak alkaline $\mathrm{pH}(8.0)$ followed by neutral $\mathrm{pH}(\sim 7.6)$. N2 exhibited initial neutral $\mathrm{pH}(\sim 7.1)$ followed by final weak acidic $\mathrm{pH}(\sim 6.98)$.
The null hypothesis of this study was rejected: a significant difference in solubility percentages among the root canal sealers tested has been shown. Furthermore, the findings of this study demonstrated that BioRoot ${ }^{\text {TMRCS }}$ and TotalFill BC Sealer showed significantly higher solubility among the tested materials with a weight loss higher than $3 \%$.

Many studies investigated the solubility of root canal sealers (2). ZnOE sealers are generally related with a certain degree of weight loss after storage in water, varying approximately from less than $1 \%$ to $7 \%$ (18). Calcium hydroxide-containing sealers are also believed to be soluble over time (18). Epoxy resin-based sealers have a relatively low solubility in water (18). MTAbased sealers have been reported to fulfill the require- 
ments of the International Standard Organization 6876, demonstrating a weight loss of less than 3\% (19).

In the present study BioRoot ${ }^{\mathrm{TM}} \mathrm{RCS}$ and TotalFill BC Sealer showed significantly higher solubility among the tested materials and they reported a weight loss higher than $3 \%$. This is in agreement with a study by Borges et al. (20), which demonstrated that solubility of bioceramic sealer iRoot SP didn't meet ANSI/ADA requirements: high solubility is the result of hydrophilic nanosized particles, which increases their surface area and allows more liquid molecules to come into contact with the sealer. However, Literature contains conflicting results: Viapiana et al. (1) found high solubility of MTAFillapex, while Zhou et al. (10) reported that solubility of the biocearmic sealer EndoSequence BC is consistent with ISO 6876/2001. The discrepancy between the results of these Authors may be attributed to variations in the methods used to dry the samples after having subjected them to solubility testing. The freshly published article by Lee et al. (20) showed that Endosequence BC Sealer and MTA Fillapex were not set in humid incubator condition even after one month, so non-complete setting of these root canal sealers should be another reason for higher solubility. Lee et al. (21) concluded that both BC Sealer and MTA Fillapex are showed to not fulfill the required chemical and physical properties as ideal root canal sealers.

An alkaline pH may contribute to osteogenic potential, biocompatibility, and antibacterial ability of root canal sealers $(8,10,21)$. The calcium hydroxide sealer tested $\left(\right.$ Sealapex $\left.{ }^{\mathrm{TM}}\right)$ demonstrated the higher alkalinity $(\mathrm{pH}>$ 9), epoxy resin-based sealers tested (EasySeal and AH plus) showed a fair alkalinity (followed by a neutral $\mathrm{pH}$ at $24 \mathrm{hrs}$ for $\mathrm{AH}$ Plus), the $\mathrm{ZnOE}$ sealers reported an initial weak alkaline $\mathrm{pH}(8.0)$ followed by a neutral $\mathrm{pH}$ $(\sim 7.6)$ for Pulp Canal Sealer ${ }^{\mathrm{TM}}$ and an initial neutral $\mathrm{pH}$ $(\sim 7.1)$ that followed by a final weak acidic $\mathrm{pH}(\sim 6.98)$ for N2.

Recent studies indicated that the resin-based sealers like AH Plus are characterized by a slightly neutral $\mathrm{pH}$ and low solubility (22). This concept was confirmed by Faria-Júnior et al. (23): the neutral $\mathrm{pH}$ and its low solubility may reduce the antibacterial activity of the sealer.

The bioceramic-based sealers (BioRoot ${ }^{\mathrm{TM} R C S}$ and Totalfill BC Sealer) exhibited high alkaline $\mathrm{pH}$ over time, significantly lower than the other tested materials. MTA fillapex reported an initial neutral $\mathrm{pH}$ (7.68) that was followed by a weak alkaline $\mathrm{pH}$ (8.02). Various studies supported these findings about bioceramic-based sealers: their $\mathrm{pH}$ is ranging between $10-12$ for some weeks after setting $(10,22)$. Silva et al. (24) showed that the initial $\mathrm{pH}$ of MTA-Fillapex was few alkaline $(\mathrm{pH}=9.3)$ and gradually declined over time to 7.76 after one week. A strong alkaline $\mathrm{pH}$ is supposed to encourage a prolonged setting time and a long-lasting antibacterial effect that eliminates the residual microorganisms survived along dentinal walls. Silva et al. (24) suggested that MTA-Fillapex, due to high alkalinity, is able to release hydroxyl ions, thereby causing a high $\mathrm{Ca} 2+$ ion release. The alkaline behaviour could contribute to hard tissue formation by activating alkaline phosphatase, neutralize the lactic acid from osteoclasts and prevent dissolution of mineralized components of teeth, prevent the bone destruction and allow tissue repair with hydroxyapatite formation (25). In Lee et al. study (21) the $\mathrm{pH}$ value of three different bioceramic-based root canal sealers remained significantly higher than that of epoxy resinbased sealers for 24 hours, with the highest alkaline $\mathrm{pH}$ measured from BC Sealer for the entire period of evaluation.

\section{Conclusions}

Based on the present results, the tested root canal sealers are showed to fulfill the required solubility properties, except the BioRoot ${ }^{\mathrm{TM}} \mathrm{RCS}$ and TotalFill BC Sealer. Even if $\mathrm{pH}$ values may encourage their biological and antimicrobial behaviour over time, the BioRoot ${ }^{\mathrm{TM}} \mathrm{RCS}$ and TotalFill BC Sealer should be improved to reduce their solubility and to increase their ability to prevent apical leakage. Further clinical trial tests and long term follow-up studies would be highly valuable to evaluate the bioceramic sealers' clinical performances.

\section{References}

1. Viapiana R, Flumignan DL, Guerreiro-Tanomaru JM, Camilleri J, Tanomaru-Filho M. Physicochemical and mechanical properties of zirconium oxide and niobium oxide modified Portland cement-based experimental endodontic sealers. Int Endod J. 2014;47:437-48.

2. Schafer E, Zandbiglari T. Solubility of root-canal sealers in water and artificial saliva. Int Endod J. 2003;36:660-9.

3. Grossman L Endodontic Practice. Ed. 11, Lea \& Febiger, Philadelphia, PA. 1988.

4. Torabinejad M, Walton RE. Endodontics Principles and practice. Saunders Elsevier, St. Louis, MO. 2009.

5. Orstavik D, Nordhal I, Tibbals JE. Dimensional change following setting of root canal sealer materials. Dent Mater. 2001;17:146-51.

6. Silva EJ, Perez R, Valentim RM, Belladonna FG, De-Deus GA, Lima IC, Neves AA. Dissolution, dislocation and dimensional changes of endodontic sealers after a solubility challenge: A micro-CT approach. Int Endod J. 2016. Mar 22. [Epub ahead of print].

7. Poggio C, Lombardini M, Conti A, Rindi S. Solubility of root-endfilling materials: a comparative study. J Endod. 2007;33:1094-7.

8. Stuart CH, Schwartz SA, Beeson TJ, Owatz CB. Enterococcus faecalis: its role in root canal treatment failure and current concepts in retreatment. J Endod. 2006;32:93-8.

9. Okabe T, Sakamoto M, Takeuchi H, Matsushima K. Effects of $\mathrm{pH}$ on mineralization ability of human dental pulp cells. J Endod. 2012;32:198-201.

10. Zhou H, Shen Y, Zheng W, Li L, Zheng Y, Haapasalo M. Physical Properties of 5 root canal sealers. J Endod. 2013;39:1281-6.

11. Zhou HM, Du TF, Shen Y, Wang ZJ, Zheng YF, Haapasalo M. In vitro cytotoxicity of calcium silicate-containing endodontic sealers. J Endod. 2015;41:56-61.

12. Kogan P, He J, Glickman GN, Watanabe I. The effects of various additives on setting properties of MTA. J Endod. 2006;32:569-72.

13. Gomes-Filho JE, Rodrigues G, Watanabe S, Estrada Bernabe PF, Lodi CS, Gomes AC. et al. Evaluation of the tissue reac- 
tion to fast endodontic cement (CER) and Angelus MTA. J Endod. 2009;35:1377-80.

14. Salles LP, Gomes-Cornelio AL, Guimaraes FC, Herrera BS, BaoSN, Rossa-Junior C. et al. Mineral trioxide aggregate-based endodontic sealer stimulates hydroxyapatite nucleation inhuman osteoblast-like cell culture J Endod. 2012;38:971-6.

15. Candeiro GT, Correia FC, Duarte MA. et al. Evaluation of radiopacity, $\mathrm{pH}$, release of calcium ions, and flow of a bioceramic root canal sealer. J Endod. 2012;38:842-5.

16. Atmeh AR, Chong EZ, Richard G, Festy F, Watson TF. Dentincement interfacial interaction: calcium silicates and polyalkenoates. J Dent Res. 2012;91:454-9.

17. Fridland M, Rosado R. MTA solubility: a long term study. J Endod. 2005;31:376-9.

18. Poggio C, Arciola CR, Dagna A, Colombo M, Bianchi S, Visai L. Solubility of root canal sealers: a comparative study. International Journal of Artificial Organs. 2010;33:676-81.

19. Vitti RP, Prati C, Silva EJ. et al. Physical properties of MTA fillapex sealer. J Endod. 2013;39:915-8.

20. Borges RP, Sousa-Neto MD, Versiani MA. et al. Changes in the surface of four calcium silicate-containing endodontic materials and an epoxy resin-based sealer after a solubility test. Int Endod J.2012;45:419-28.

21. Lee JK, Kwak SW, Ha JH, Lee WC, Kim HC. Physicochemical Properties of Epoxy Resin-Based and Bioceramic-Based Root Canal Sealers. Bioinorganic Chemistry and Applications, Volume 2017, Article ID 2582849, doi:10.1155/2017/2582849. 2017.

22. Marciano MA, Guimaraes BM, Ordinola-Zapata R, Bramante $\mathrm{CM}$, Cavenago BC. et al. Physical properties and interfacial adaptation of three epoxy resin-based sealers. J Endod. 2011;37:1417-21.

23. Faria Junior NB, Tanomaru-Filho M, Berbert FL, GuerreiroTanomaru JM. Antibiofilm activity, $\mathrm{pH}$ and solubility of endodontic sealers. Int Endod J.2013;46:755-62.

24. Silva EJ, Rosa TP, Herrera DR, Jacinto RC, Gomes BP. et al. Evaluation of cytotoxicity and physicochemical properties of calcium silicate-based endodontic sealer MTA Fillapex. J Endod. 2013;39:274-7.

25. Zhang W, Li Z, Peng B. Ex vivo cytotoxicity of a new calcium silicate-based canal filling material. Int Endod J.2010;43:769-74.

\section{Conflict of Interest}

The authors have declared that no conflict of interest exist. 